\title{
ASPECTOS RELACIONADOS À FISIOLOGIA DO ANESTRO PÓS-PARTO EM BOVINOS
}

\author{
Moacir Ferreira Duarte Júnior, Luciana Keiko Hatamoto-Zervoudakis, Joanis Tilemahos \\ Zervoudakis, Jefferson Fabiano Werner Kocheck, Ricardo Sérgio Fioravanti Filho, Leodil da Costa \\ Freitas
}

Universidade Federal do Mato Grosso - UFMT, Cuiabá-MT.

Correspondência para: Moacir Ferreira Duarte Júnior - moacirjunior_vet@hotmail.com

\section{RESUMO}

Para chegar a uma pecuária eficiente e lucrativa é preciso a cada dia melhorar os índices zootécnicos de produção, tornando a atividade cada vez mais sustentável. O Brasil possui o maior rebanho bovino comercial do mundo, mas apresenta índices de eficiência reprodutiva abaixo do potencial. A fertilidade pós-parto é negativamente influenciada pelo anestro, que pode ser um indicativo de condições inadequadas, como subnutrição ou condições patológicas. $O$ anestro pósparto é um estado de completa inatividade sexual que compreende o período do parto até a manifestação do primeiro cio fértil. Diversos fatores podem influenciar no período de anestro, entre eles interação mãe-cria, balanço energético negativo, déficit de progesterona, escore de condição corporal e deficiência de alguns metabólitos essenciais à reprodução. Esses mecanismos fisiológicos podem agir separadamente ou em conjunto de forma a atrasar ou impedir a ovulação, prejudicando a eficiência reprodutiva das fêmeas de cria do rebanho. Objetivou-se com esta revisão abordar os principais mecanismos fisiológicos relacionados diretamente com o anestro pós-parto em bovinos, e estratégias que visem minimizar esse período de retorno a atividade reprodutiva.

Palavras chave: aciclicidade; concepção; fertilidade; ovulação; puerpério.

\section{ASPECTS RELATED TO THE PHYSIOLOGY OF POSTPARTUM ANESTRUS IN BOVINE}

\begin{abstract}
To achieve successful profitability and efficiency in livestock production it is important to improve productivity indexes every day, in order to turn the activity sustainable. Brazil has the world's largest herd of commercial cattle, but the current reproductive efficiency levels are inadequate . The postpartum fertility is negatively influenced by prolonged anestrus, which can be an indicative of inadequate conditions, such as inadequate nutrition or pathological conditions. The postpartum anestrus is a condition of complete sexual inactivity. It comprises the period of calving until the first fertile ovulation. Several factors can influence the anestrus period, including cow-calf interaction, negative energy balance, progesterone deficit, low body condition score and lack of some essential reproductive metabolites. These mechanisms can act separately or together delaying or inhibiting ovulation, which can decrease the reproductive efficiency of females of the herd. This review aimed to address the main physiological mechanisms directly related with the postpartum anestrus in bovine, and the strategies that intend to reduce this period of return to the reproductive activity.
\end{abstract}

Keywords: acyclicity; conception; fertility; ovulation; puerperium. 


\section{INTRODUÇÃO}

Durante a vida reprodutiva de uma matriz, por diversas fases, a nutrição está fortemente correlacionada. A prioridade por energia e nutrientes pelos diversos órgãos varia de acordo com o status fisiológico em que se encontra o animal. Fisiologicamente o sistema reprodutivo tem prioridade baixa quando comparado ao sistema nervoso, por exemplo. Dessa forma, animais em déficit nutricional terão órgãos e tecidos com baixa prioridade prejudicados (PIRES et al., 2011).

A melhoria da eficiência reprodutiva dentro do sistema de produção bovino deve ser uma das metas quando se busca aumentar a receita por vaca por ano e justificar a implantação de biotécnicas de manejo reprodutivo. 0 desempenho reprodutivo é um fator limitante na produção de bovinos de corte (MORALES; CAVESTANY, 2012) e está diretamente relacionado com o período de serviço e com o intervalo entre partos, uma vez que sua ampliação diminui o número de crias durante a vida reprodutiva da matriz (BORGES et al., 2009).

É importante que os animais iniciem a vida reprodutiva e tenham o primeiro parto em idade mais precoce, dentro dos limites fisiológicos, e que restabeleçam a função ovariana num curto período após o parto (BORGES et al., 2009). Diversos mecanismos fisiológicos atuam isoladamente ou em conjunto com outros fatores, interrompendo o mecanismo endócrino do eixo hipotálamohipófise-gonadal que, por sua vez, controla a manifestação do estro e a subsequente ovulação (RABASSA et al., 2007).

O anestro pós-parto é caracterizado pela inatividade sexual, sem manifestação de cio, neste período o trato reprodutivo se recupera da gestação anterior até que a funcionalidade do eixo hipotálamo-hipófiseovário-útero esteja pronta para uma nova gestação (CAMPOS et al., 2012).

O objetivo desta revisão é abordar os principais mecanismos fisiológicos relacionados diretamente com o anestro pósparto em bovinos, e estratégias que visem minimizar esse período de retorno à atividade reprodutiva.

\section{REVISÃO DE LITERATURA}

Os fatores que contribuem para perdas econômicas na bovinocultura são: anestro pós-parto, baixa taxa de concepção no primeiro serviço, perdas embrionárias e doenças reprodutivas. O período de anestro pós-parto determina, em grande parte, se a fêmea vai manter uma produção esperada de uma cria por vaca por ano, que é considerado uma das variáveis mais sensíveis que compõe o cálculo de evolução do rebanho de uma propriedade (LAMB, 2009). Em rebanhos de bovinos de corte, o desempenho reprodutivo 
das fêmeas deve assumir importância igual à eficiência econômica, uma vez que a produtividade do sistema é reflexo da produtividade dos animais, sendo a venda de bezerros desmamados importante receita para atingir as metas econômicas desejáveis (MWANSA et al., 2002). Perotto et al. (2006) destacam que a redução no intervalo entre partos proporciona maior retorno econômico sobre os custos fixos e operacionais investidos no rebanho de cria, já que o aumento da taxa de natalidade e desmama reflete no aumento da receita da propriedade.

Um longo período de anestro pósparto é um dos principais fatores responsáveis pelo aumento do período de serviço e consequentemente prolongado intervalo entre partos causando baixa eficiência reprodutivo do rebanho (ATANASOV et al., 2012). Objetivando-se a obtenção de uma cria/vaca/ano dentro do rebanho, o intervalo entre parto-concepção não deve exceder 80-85 dias, levando em conta um período gestacional de aproximadamente 280 dias (YAVAS; WALTON, 2000).

O puerpério, ou período pós-parto, é o período que se estende do parto até que o organismo e o aparelho reprodutivo da fêmea retornem às condições fisiológicas normais de ciclicidade. Nesse período ocorre a involução uterina, onde ocorre eliminação de patógenos e regeneração endometrial até a restauração do útero (HAFEZ; HAFEZ, 2004). Após o parto, o útero bovino chega a medir 1 metro e pesar cerca de 10kg. Em torno de 20 a 30 dias, após a involução macro e microscópica, o útero pesa aproximadamente $1 \mathrm{~kg}$ e tem $5 \mathrm{~cm}$ de diâmetro (GONZÁLEZ, 2002). Em geral, o útero leva cerca de 3-4 semanas para retornar ao seu tamanho normal, porém o tempo de regeneração do epitélio varia entre 40-50 dias. O útero após o parto depende de processos de reparação como migração de linfócitos para o lúmen uterino para fagocitar microrganismos patógenos presentes no pósparto, liberação de prostaglandina principalmente durante as duas primeiras semanas pós-parto, estimulando contrações do miométrio, expulsão de líquidos e tecidos ainda presentes e secreção de estrógeno antes da primeira ovulação, tornando o útero mais resistente às infecções (HAFEZ; HAFEZ, 2004).

Fernandes et al. (2012) afirma que existe correlação entre 0 período de involução uterina e retorno a ciclicidade da fêmea influenciando na fertilidade subseqüente. Fêmeas sem complicações puerperais apresentam período de inatividade ovariana menor do que aquelas com anormalidades puerperais, sendo que as prostaglandinas $F 2 \alpha$ exercem importante função no processo de involução uterina. 
Outros fatores também estão diretamente relacionados com o retorno da ciclicidade das fêmeas no pós-parto, como, restabelecimento da concentração de LH (hormônio luteinizante) na hipófise (SOUZA et al., 2009), escore de condição corporal (CAMPOS et al., 2012), presença da cria ao pé (ESPASANDIN et al., 2001), estimulo da mamada, balanço energético negativo (PINHEIRO et al., 2013) e efeito da presença do macho (GOKULDAS et al., 2010).

Portanto, para ocorrer a retomada da atividade cíclica em vacas de corte, é necessária adequada liberação de gonadotrofinas que são influenciadas por fatores fisiológicos e patológicos no pré e pós-parto (YAVAS; WALTON, 2000). No entanto, após o parto a fêmea bovina tem que criar um bezerro saudável e em seguida restabelecer uma nova gestação. Para isso é necessário que ocorram alterações no padrão de desenvolvimento folicular que leve o animal a apresentar cio, ovular e formar um corpo lúteo capaz de manter uma nova gestação (RHODES et al., 2003).

Wiltbank et al. (2002), associaram a diminuição da concentração de gonadotrofinas no final da gestação a uma intensa retroalimentação negativa do estrógeno e progesterona. Ainda, os autores verificaram elevação das concentrações de FSH (hormônio folículo estimulante) e, subsequente, emergência da primeira onda folicular de 2 a7 dias pós-parto; quando após liberação do feto e placenta, ocorre redução na concentração de estrógenos, não havendo mais restrição ao FSH (WILLIAMS, 2001). No entanto, uma ausência de pulsatilidade adequada de $\mathrm{LH}$, impede que essas estruturas se desenvolvam além do diâmetro de divergência folicular, culminando em atresia folicular (WILTBANK et al., 2002).

Em caso de boas condições nutricionais dos animais, estima-se que no terço final da gestação os estoques de LH são reduzidos em até 90-95\% (WILLIAMS, 2001). Entretanto, para que ocorram maturação e ovulação folicular é preciso que existam níveis suficientes de $\mathrm{LH}$, que deve ser produzido e estocado na hipófise. Entretanto, a ocorrência dessa reposição necessita de duas a três semanas após o parto, independente de amamentação (WILLIAMS, 2001). Bó et al. (2003), afirmam que para que ocorra a ovulação do folículo dominante, a freqüência dos pulsos de LH deve ser de aproximadamente 1 pulso por hora para que a máxima produção de estradiol seja adequadamente estimulada. No entanto, segundo Yavas e Walton (2000), após o parto verifica-se baixa amplitude e frequência desses pulsos, ocorrendo na frequência de aproximadamente 1 pulso a cada 4 horas.

O impedimento da liberação de $\mathrm{GnRH}$ (hormônio liberador de gonadotrofinas), FSH e $\mathrm{LH}$ podem bloquear a atividade ovariana 
(HAFEZ; HAFEZ, 2004). Assim, a aciclicidade no período pós-parto pode ser causada pela inibição em vários níveis do eixo hipotálamohipófise-gonadas. O estado nutricional dos animais tem efeitos positivos e negativos na reprodução, mediados diretamente por nutrientes da dieta ou indiretamente via sistema endócrino. Como mediadores nutricionais, podemos citar a glicose, insuficiência gliconeogênica, aminoácidos, neuro-hormônios, insulina e IGF-I (PIRES et al., 2011). Além disso, hormônios como a leptina, que são secretados principalmente pelos adipócitos branco, também tem influência direta no eixo reprodutivo, agindo no sistema nervoso central e sinalizando sobre o estado nutricional do animal. Este hormônio regula o consumo alimentar, o balanço energético e o peso corporal do animal (BOLAND et al., 2001).

\section{Estímulo da mamada}

A influência da amamentação no retorno a ciclicidade reprodutiva em bovinos tem sido alvo de muitos estudos. No entanto, ainda hoje os resultados são um pouco contraditórios no que diz respeito ao mecanismo exato, sendo levantadas diversas hipóteses que possam justificar o efeito depressor da amamentação sobre o ciclo reprodutivo de vacas no pós-parto (CUBAS et al., 1985).

Segundo Santos et al. (2003), a amamentação é um dos efeitos mais críticos sobre o retorno a ciclicidade após o parto de vacas de corte. Uma relação muito forte entre mãe e sua cria, pode desencadear um processo neuroendócrino que atrasa o retorno ao estro na maioria das fêmeas, principalmente nesta espécie. Somente cerca de $10-30 \%$ das fêmeas bovinas retornam a atividade ovariana normal deixando o anestro pós-parto nos primeiros 60 dias, devido à amamentação e influência do balanço energético negativo (PONSART et al., 2000).

O anestro lactacional pós-parto não é causado somente pela sucção do leite e estímulos na região das glândulas mamárias e flanco da mãe, mas também por interação e sentidos sensoriais de reconhecimento materno (visão, audição e olfação) (SANTOS et al., 2003).

Pinheiro et al. (2013) relata que a produção de $\mathrm{GnRH}$ nos primeiros 30 dias pósparto é reduzida por alterações fisiológicas decorrentes do parto, mas não totalmente suprimida, sendo que a partir da quinta semana aproximadamente, um dos fatores que bloquearia a ciclicidade seria por influência da amamentação, quando o eixo hipotálamo-hipófise-gonadal já estaria plenamente funcional.

O mecanismo exato no qual a mamada e a presença da cria ao pé alteram a função reprodutiva não é bem elucidado, no entanto, essa interação mãe-cria gera 
mensagens metabólicas neurais e induz a liberação de hormônios reguladores (opióides, glicocorticóides, prolactina) que gera efeito inibitório na liberação de $\mathrm{GnRH}$ e/ou LH, ou ainda uma incapacidade da hipófise em responder adequadamente ao estímulo do GnRH. Essa supressão imediata da atividade ovariana durante o pós-parto imediato é uma característica de vacas de corte amamentando suas crias (PETER et al., 2009a). Neste sentido, Williams (2001), cita que a sucção do leite e a presença da cria ao pé criam mensagens neurais e fisiológicas, que juntas diminuem a resposta da adeno hipófise ao GnRH ou inibem a síntese e secreção de LH por ela.

Faltys et al. (1987), citaram duas hipóteses no qual a amamentação poderia suprimir a secreção de LH: primeiro, que o estímulo neural associado com amamentação atuaria diretamente no hipotálamo e hipófise, e que num período curto após o parto aumentaria a sensibilidade do centro tônico do hipotálamo para o feedback negativo a baixos níveis de estrógenos circulantes, desencadeando menor liberação de $\mathrm{GnRH}$, menor liberação de LH e resultando menor produção de estrógenos pelos folículos ovarianos, que não seriam suficientes para estimular o pico préovulatório de LH na hipófise. Dessa forma, a remoção do estímulo da mamada decresceria a sensitividade do hipotálamo para baixos níveis de estrógenos, com aumento na produção de $\mathrm{GnRH}$; Uma segunda hipótese consiste em que a supressão de GnRH e LH seria modulado pela liberação de opióides, glicocorticóides e prolactina durante a amamentação.

Williams et al. (1993), em estudos com vacas no qual a inervação do úbere foi bloqueada cirurgicamente, mostraram que a mensagem neural direta do estímulo da mamada, não é necessária para a supressão de liberação de $\mathrm{GnRH}$ e LH, sendo a presença física do bezerro suficiente para esse efeito. Corroborando com Short et al. (1976) (apud LAMB, 2009), que realizou ablação dos nervos sensoriais das glândulas mamárias durante a primeira semana após o parto, os autores verificaram que o intervalo do parto até o primeiro estro foi semelhante aos das vacas intactas, que amamentavam seus bezerros, indicando que o bezerro estava influenciando o anestro pós-parto de sua mãe por outros estímulos que não apenas a manipulação do teto. Neste sentido, Steveson et al. (1994), trabalharam com vacas mastectomizadas na presença de seus bezerros, e observaram prolongamento do intervalo pós-parto, sendo esse intervalo semelhante ao de vacas intactas com seus bezerros ao pé, demonstrando que a associação vaca-bezerro, com este tentando mamar, foi parcialmente responsável por intervalos prolongados de anestro, mesmo 
sem a glândula mamária intacta. Também os níveis de cortisol, ocitocina e prolactina foram aumentados devido a essa interação mãe-cria, levando a conclusão de que vacas mastectomizadas que "amamentavam" respondiam de forma semelhante aos animais com úberes intactos. Adicionalmente, Lamb et al. (1997), mostraram que o contato na região inguinal e estímulo da mamada de bezerros estranhos também mimetizaram tais efeitos supressivos.

Em estudos buscando observar o efeito do estímulo da mamada e do contato inguinal, vacas mastectomizadas foram colocadas em baias individuais onde somente era possível o contato entre mãe e bezerro na região do pescoço e cabeça. Resultados deste estudo mostraram que o intervalo entre parto e retorno a ciclicidade em vacas com acesso restrito e de vacas com bezerros desmamados foram similares, porém, mais curtos em comparação com vacas mastectomizadas ou com úbere intacto na presença do bezerro, indicando o efeito do contato inguinal como responsável por prolongar o anestro, quer a vaca seja mastectomizada ou tenha úbere intacto (LAMB, 2009). Interessante notar ainda que tais efeitos não são observados em ordenhas mecânicas, quando vacas de corte submetidas a duas ou cinco ordenhas mecânicas por dia, na presença ou ausência do seu bezerro não apresentaram prolongamento do anestro, enquanto que em mesmas condições vacas com bezerro ao pé mamando pelo menos duas vezes ao dia prolongou 0 anestro pós-parto. Aparentemente, a ordenha mecânica não simula a percepção da amamentação, mesmo na presença do bezerro, reforçando a importância da interação mãe-cria na influência do anestro pós-parto (LAMB et al., 1999).

O estímulo da mamada tem sido associado à produção de peptídeos opióides endógenos (POE), que decresce à medida que prolonga o intervalo pós-parto. Entre os POE produzidos pelo cérebro e adeno hipófise a $\beta$-endorfina é o POE mais potente. Eles agem nos neurônios produtores de GnRH por ação direta, inibindo sua liberação que, por sua vez, inibe a secreção de LH (YAVAS; WALTON, 2000).

Os opióides de natureza endógena são substâncias produzidas no sistema nervoso central, ou neuropeptídeos, que na verdade são hormônios peptídeos, biologicamente inativos, que darão origem a agentes ativos após segmentação enzimática. Pertencem a três famílias de opióides neuropeptídeos: as dinorfinas, as encefalinas e as endorfinas, que são importantes no mecanismo fisiológico de supressão de dor. Os opióides bloqueiam os sinais nociceptivos, sem alterar as demais formas de 
sensibilidade. Estes apresentam ação direta no sistema nervoso central e periférico, ligando-se a seus receptores (TRIBIOLI, 2004). Os peptídeos derivados da propiomelanocortina são sintetizados na adeno-hipófise, núcleo arqueado do hipotálamo, no núcleo tractus solitarius e na placenta. A $\beta$-endorfina liga-se a receptores $\mu$, presentes em grandes quantidades no hipotálamo, e receptores $\delta$, participando de forma direta ou indireta na inibição da atividade neuronal de produção de $\mathrm{GnRH}$, além de agirem na hipófise inibindo a liberação de $\mathrm{LH}$ e FSH, e indiretamente nas gônadas por alterações do efeito estimulatório das gonadotrofinas na secreção de esteróides sexuais (RIVIER; RIVEST, 1991).

A concentração de $\beta$-endorfinas no hipotálamo é negativamente correlacionada com a produção de GnRH pelo hipotálamo. Além disso, a concentração de RNAm para propiomelanocortina (precursor de $\beta$ endorfinas) pelo hipotálamo é maior em fêmeas amamentando do que em fêmeas que não estão sendo sua concentração negativamente correlacionada com a concentração de LH. Dessa forma, a presença desses opióides pode influenciar o retorno à atividade ovariana pós-parto, inibindo produção de $\mathrm{GnRH}$ pelo hipotálamo e subseqüente secreção de LH pela hipófise (BYERLEY et al., 1993 apud RABASSA et al., 2007).
A concentração de opióides endógenos encontra-se muito aumentada no parto, quando se torna necessária a receptividade da mãe em relação ao bezerro, um período que pode ser considerado crítico. Antes mesmo do parto, o feto secreta essas substâncias que ajuda a criar essa relação mãe-cria. Este aumento ocorrido no parto, em resposta à sensação de dor, mantém-se durante o inicio da lactação em vacas amamentando suas crias (LAMB et al., 1999).

Estudos demonstram bem o efeito dos opióides endógenos interagindo no eixo reprodutivo e na regulação de secreção de LH. Peck et al. (1998) demonstraram que administração de morfina (agonista opióide), 36 horas após remoção dos bezerros diminuiu os níveis séricos de concentração de LH, a frequência de pulsos de LH hipofisário e a resposta ao hormônio liberador de $\mathrm{LH}$, e ainda o incremento de secreção de prolactina em vacas de corte.

Outros estudos utilizando administração de naloxone (antagonista opióide) em vacas anovulatórias pós-parto lactantes promoveu aumento da frequência de pulsos de LH (WHISNANT et al., 1986; GREGG et al., 1986). A naloxone, por ser um opióide antagonista, impede o acesso do agonista, revertendo sua ação biológica. Esta substância possui estrutura semelhante ao agonista, para efeito de reconhecimento do receptor (AZEVÊDO, 1998). 
Ahmadzadech et al. (1998), também avaliaram o efeito da naloxona sobre a secreção de LH pela hipófise em vacas anovulatórias no período pós-parto, quando vacas leiteiras estavam em balanço energético negativo. Os autores verificaram que a naloxona $(1 \mathrm{mg} / \mathrm{kg}$ peso corporal IV 15 dias pré-parto) causou um aumento transitório nas concentrações séricas de LH após 45 minutos da administração, o que não ocorreu em vacas do grupo controle (soro fisiológico/placebo), sugerindo que a modulação de secreção de LH, ao menos em parte, pode ser mediada através dos opióides endógenos antes da primeira ovulação pósparto.

Resultados semelhantes foram encontrados por Kadokawa e Yamada (1999), quando utilizaram injeção intravenosa de naltrexona, um antagonista do receptor opióide que tem maior duração de ação do que a naloxona. Estes autores verificaram aumento dos picos de LH por hora e dos níveis séricos de LH no período pós-injeção comparados ao período pré injeção $(0,85 \pm 0,29$ vs $1,24 \pm 0,17 P<0,05$, e $1,81 \pm 0,70$ vs $2,47 \pm 0,92 \mathrm{ng} / \mathrm{ml}, \quad \mathrm{P}<0,05$, respectivamente). Em contraste, todos os parâmetros de pulsos de LH permaneceram inalterados no grupo controle, sugerindo que injeções de naltrexona ativam o pulso de LH.

A amamentação realizada mais de 2-3 vezes por dia, ou o aumento na frequência de ordenhas, aumenta os níveis de opióides endógenos, diminuindo a liberação de $\mathrm{GnRH}$ e LH, impedindo a maturação final do folículo para o estágio pré ovulatório, e, portanto, prolongando o período de anovulação. Por outro lado a amamentação é importante por melhorar o tônus e a involução uterina (SQUIRES, 2011). O teto contêm sensores neurais que sofrem impulsos durante a amamentação que vão até o hipotálamo, estes estímulos chegam à neuro hipófise estimulando secreção de ocitocina que é liberada na corrente sanguínea (SENGER, 2003). Esta ocitocina se liga a receptores específicos no endométrio ativando a fosfolipase C e a liberação de inositol fosfatase e diacilglicerol, levando a uma mobilização intracelular de $\mathrm{Ca} 2+$, acompanhada pelo aumento na secreção de PGF2 $\alpha$ (DURAS et al., 2005) que aumenta as contrações miometriais, levando a completa regressão uterina (SENGER, 2003). Portanto, é preciso uma amamentação por cerca de 10 dias a fim de evitar involução uterina inadequada (SQUIRES, 2011).

O reinicio da função cíclica normal ocorre em duas etapas. Inicialmente, entre duas e cinco semanas, ocorrem síntese e armazenamento de LH pela hipófise, requerendo baixos níveis de $\mathrm{GnRH}$ pelo hipotálamo, já na segunda etapa onde irá ocorrer crescimento folicular, aumento na produção de estradiol pelos folículos e 
posterior ovulação é necessário aumento na liberação pulsátil de LH. Essa liberação pulsátil de LH é impedida em vacas manejadas com bezerro ao pé amamentando (PARRA; BELTRAN, 2008).

Mancio et al. (1999), avaliaram diferentes manejos de mamadas em bovinos de corte criados a pasto, sendo: controlada uma vez ao dia, livre e interrompida. Os autores observaram influência dos tratamentos no aparecimento do primeiro estro durante a estação de monta, onde as vacas que amamentaram seus bezerros apenas uma vez ao dia manifestaram estro antecipado e maior taxa de fertilidade, refletindo em um subseqüente aumento na taxa de natalidade. Desta maneira, demonstrou-se que essa prática de manejo é eficiente para reduzir o período de anestro causado pelo efeito da amamentação.

Adicionalmente, o manejo de desmama precoce melhora os índices de eficiência reprodutiva do rebanho, uma vez que induz ao aumento da secreção de $\mathrm{LH}$ pós-parto e reduzindo significativamente 0 intervalo do parto à primeira ovulação em vacas multíparas, e ainda proporciona condições de aumento de ganho de peso das fêmeas desmamadas (PINHEIRO et al., 2013).

Outro mecanismo frequentemente relacionado ao efeito da amamentação e prolongamento do anestro pós parto são os efeitos dos glicocorticoides. Estes tem ação direta na lactogênese e a remoção do leite é associada à aumentos dos seus níveis séricos. Seus efeitos sobre a ciclicidade pós-parto não são bem explicados, no entanto, estudos apontam que estes podem atuar inibindo o retorno a ciclicidade, ainda que este efeito nem sempre seja encontrado em vacas amamentando (CONVEYB et al. 1983 apud RABASSA et al., 2007).

Alguns autores relataram maiores concentrações de glicocorticóides em animais amamentando quando comparados a animais não lactantes ou ordenhadas. Dessa forma poderia ser o hormônio que modula negativamente os eventos reprodutivos pós-parto (KANCHEV et al., 1976 apud FALTYS et al., 1987). Ele agiria induzindo a liberação conjunta de oxitocina e ADH (hormônio antidiurético) que funciona como agente liberador de ACTH (Hormônio adrenocorticotrófico) que atua na glândula adrenal estimulando-a a sintetizar e liberar seus hormônios, principalmente o glicocorticóides que se liga a zona fasciculada reduzindo a secreção do $\mathrm{GnRH}$ e $\mathrm{LH}$ por um mecanismo de "feedback" negativo (FERREIRA, 1992). Porém Faltys et al. (1987), não observou esse efeito quando avaliou a ocorrência de redução da afinidade da transcortina (uma glicoproteína) pelo cortisol em vacas amamentando, levando em consideração que apenas $10 \%$ do total de cortisol do soro sanguíneo não estão ligados 
a alguma proteína, sendo esta a parcela biologicamente ativa.

Também a prolactina foi relacionada como possível reguladora da secreção de GnRH em vacas amamentando, possivelmente restringindo $\mathrm{o}$ fator inibidor de prolactina. O aumento dos níveis de prolactina seria um resultado da ativação de hormônios serotoninérgicos pelo estímulo da mamada (SMITH et al., 1981). No entanto a afirmação de que alta concentração de prolactina agiria inibindo a ciclicidade ovariana em vacas amamentando, não é bem comprovada, uma vez que o uso de agentes farmacológicos para reduzir os níveis de prolactina não afeta o ciclo ovariano (PETERS; LAMMING, 1983 apud FERREIRA, 1992).

Segundo Yavas e Walton (2000), a prolactina não está associada à falta de ovulação pós-parto em vacas de corte. Estudos realizados com dopamina (bloqueador de prolactina) em vacas no pósparto não alteraram as concentrações de gonadotrofinas e duração do anestro.

\section{Balanço energético negativo}

Segundo Leroy et al. (2009) já a algum tempo, tem se observado uma redução na fertilidade, principalmente em vacas de leite de alta produção, decorrentes do conflito entre necessidades basais e reprodutivas. 0 aumento de produção nos rebanhos é diretamente correlacionado com uma indesejada ineficiência reprodutiva, evidenciada por prolongamento do período de serviço, anestro e baixa taxa de concepção.

O balanço de energia líquida (BEL) é a diferença entre a energia consumida e a necessária para manutenção e produção (SANTOS; SÁ FILHO, 2006). Uma baixa ingestão de nutrientes antes do parto e após o parto estão associados à perda de peso, redução no desempenho reprodutivo, foliculogênese reduzida e baixa taxa de prenhez (HUSSEIN; ABDEL-RAHEEM, 2013).

Neste período, o requerimento nutricional tem um aumento excessivo, principalmente em vacas leiteiras de alta produção. No entanto, a capacidade máxima de ingestão de matéria seca ocorre somente 4 a 6 semanas após o pico de produção, resultando em perda de peso e estado de BEL negativo mais comumente chamado de balanço energético negativo (BEN), podendo se prolongar por 10-12 semanas após o parto (BELL, 1995).

Tamminga et al. (1997), em estudos avaliando o particionamento de energia no pós-parto imediato de vacas leiteiras induzidos pelo GH (hormônio do crescimento), observaram mobilização de $42 \mathrm{Kg}$ de peso corporal vazio, $31 \mathrm{Kg}$ de gordura e $5 \mathrm{Kg}$ de proteína. Mobilizando uma média de $0,7 \mathrm{Kg}$ de peso corporal vazio, $0,56 \mathrm{Kg}$ de gordura e 0,04Kg de proteína por dia, porém, 
grande parte do total de mobilização ocorreu na primeira semana pós-parto, totalizando $37 \%$ de peso corporal vazio, $12 \%$ gordura e 58\% de proteína.

Perdas de $10-15 \%$ do peso corporal nas primeiras semanas pós-parto não afetam reinicio da atividade ovariana de animais de grande porte parindo em boas condições de condição corporal. O organismo da vaca tem capacidade de ativar alguns mecanismos metabólicos quando em situações de subnutrição, retirando massas corporais por um período, sem sacrificar a eficiência reprodutiva. Porém, se a condição corporal ao parto for moderada a baixa, a excessiva perda de peso no início de lactação pode atrasar o aparecimento do primeiro estro (FERREIRA, 1993).

Durante períodos de restrição de energia, por baixa capacidade de ingestão ou baixa qualidade da dieta, substratos oxidáveis por tecidos acabam sendo priorizados para funções de manutenção celular, atividade circulatória e neuronal (SANTOS; SÁ FILHO, 2006). Dessa forma ocorre um desacoplamento do eixo somatotrópico $[\mathrm{GH}$, receptor para hormônio do crescimento (GHR) e fator de crescimento semelhante à insulina (IGF-1)], levando a um estado fisiológico catabólico, na presença de altos níveis de $\mathrm{GH}$ no sangue, baixos níveis sanguíneos de IGF-1, baixa insulina e baixa glicose sanguínea. Com isso ocorre mobilização de gordura dos tecidos, para demandar energia para altas produções de leite e "bloqueio" o eixo reprodutivo através de uma série de mecanismos, principalmente no pós-parto imediato. Em um segundo momento, após reacoplamento do eixo somatotrópico, o animal entra em estado fisiológico anabólico, diminuindo níveis de GH e aumentando insulina, IGF-1 e glicose, promovendo dessa forma retorno da saúde reprodutiva (LUCY, 2011).

Portanto, o anestro pode ser ocasionado por baixo peso corporal associado ao balanço energético negativo, onde vacas com escore de condição corporal menor que 5 (escala 1-9) podem apresentar mais de 14 ondas de crescimento folicular antes da ovulação (DRIANCOURT, 2001).

Hess et al. (2005) propuseram um modelo (Figura. 1) de regulação dos processos fisiológicos associados com o estro no pós-parto de fêmeas bovinas, apresentando os principais fatores integrados negativos e positivamente que possam induzir o retorno a ciclicidade. 


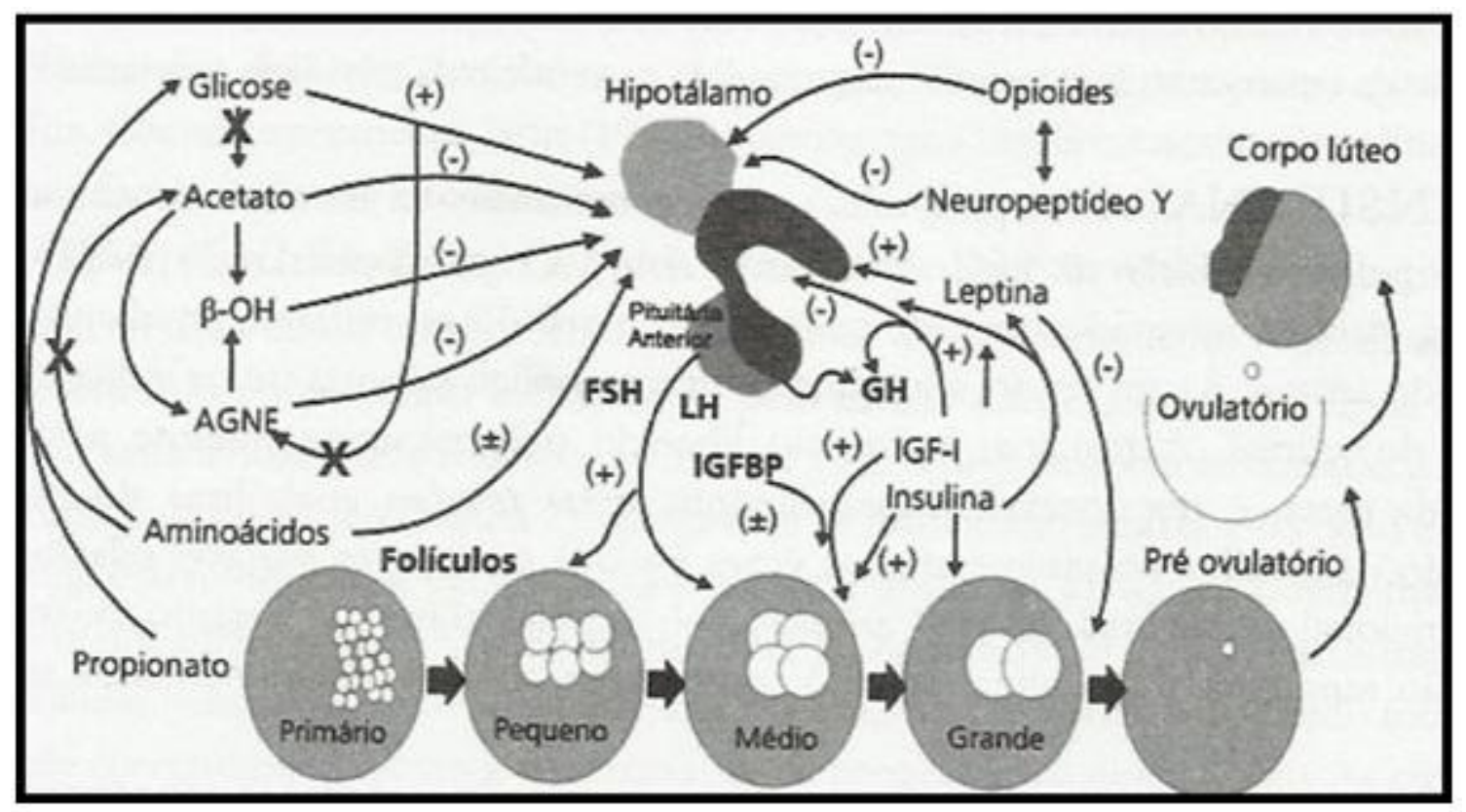

Figura.1. Esquema da regulação metabólica dos processos reprodutivos associados ao estro em bovinos. Fonte: Adaptado de Hess et al. (2005).

Segundo Jhonson et al. (1987) (apud RABASSA et al., 2007), suplementação no pós-parto com gordura acentua 0 crescimento folicular ovariano e induz crescimento folicular ao tamanho pré ovulatório, porém, não há alteração no período de anestro. Já Thomas et al. (1997) cita que a suplementação de gordura na dieta pré e pós-parto aumenta a eficiência reprodutiva por diminuir o tempo para ocorrência do primeiro estro pós-parto.

Apesar dos recentes avanços em pesquisas a cerca do eixo reprodutivo, crescimento folicular e ovulação, ainda hoje os mecanismos não foram completamente esclarecidos. São certo que as gonadotrofinas são as principais responsáveis pelo crescimento e desenvolvimento do folículo antral, mas também interagem com outros metabólitos e hormônios. Fatores extraovarianos, como mudança nutricional, mediadas por hormônios metabólicos também afetam o desenvolvimento folicular e qualidade do oócito (WEBB et al., 2004).

Para superar estes problemas de longos períodos de anestro pós parto, uma nutrição adequada deve ser fornecida, de forma a otimizar a atividade reprodutiva pós parto (HUSSEIN; ABDEL-RAHEEM, 2013).

Glicose

A glicose é um carboidrato que é utilizado como principal fonte de energia pelo sistema nervoso central. Quando em estado de subnutrição severa, o animal entra em hipoglicemia, deprimindo o sistema nervoso, reduzindo secreção de GnRH pelo 
hipotálamo e menor atividade ovariana (HESS et al., 2005).

Praticamente nenhuma glicose foge a fermentação ruminal, dessa forma, os ruminantes dependem principalmente da glicose sanguínea derivada da gliconeogênese no fígado que utiliza o ácido propiônico, um ácido graxo volátil absorvido no rúmen, como substrato. As enzimas gliconeogênicas são estimuladas pelo $\mathrm{GH}$, no entanto, apesar de altas concentrações de GH no pós-parto e intensa gliconeogênese no fígado, ainda assim, as quantidades sintetizadas pelo fígado não são suficientes para a demanda de produção de leite em vacas de alta produção, e as concentrações de glicose permanecem baixas (KNAPP et al., 1992 apud LUCY, 2011).

Em vacas no pós-parto em inicio de lactação, quando a exigência para síntese dos constituintes do leite aumenta, a glicose se torna de alta prioridade devida suprir carbono, hidrogênio e oxigênio na glândula mamária para síntese de lactose, gordura e proteína do leite. Situações de hipoglicemia pode provocar estresse ao animal e desencadear doenças metabólicas como cetose e o fígado gorduroso. Nessa fase, a glândula mamária chega a usar até $60-85 \%$ da glicose disponível pelo corpo, sendo cerca de $80 \%$ usados na síntese de lactose (CLARK, 1975). O úbere é beneficiado, pois não utiliza a insulina para facilitar a captação de glicose nas células pelas moléculas de transporte de glicose, GLUT 1 e 3, já os demais tecidos corpóreos não encontram essa facilidade expressando principalmente a GLUT 4, que é insulino-dependente (ZHAO et al., 1996 apud LEROY et al., 2009).

Em estados de jejum crônico, os níveis séricos de glicose podem baixar, devido a sua utilização oxidativa por tecidos dependentes dessa fonte como substrato energético. $\mathrm{Na}$ falta de suplemento energético há utilização de corpos cetônicos por tecidos da eminência mediana (região hipotalâmica responsável pela secreção de hormônios, entre eles o GnRH) e hipófise causando menor função ovariana posteriormente. (MCCANN; HANSEL, 1986 apud FERREIRA, 1993). Os corpos cetônicos são substância derivados da quebra dos ácidos gordos. Em situações de hipoglicemia, o cérebro pode receber até $70 \%$ de sua energia a partir desses corpos cetônicos, no entanto, devido sua quebra ser nas mitocôndrias, e estas se situarem longe dos axônios das células cerebrais, o cérebro ainda mantém certa necessidade pela glicose (GONZÁLEZ, 2002).

Assim, a utilização da glicose tem importante função no hipotálamo e na hipófise, secretando aminoácidos nesses tecidos, essenciais na formação dos hormônios peptídeos (MCCANN; HANSEL, 1986 apud FERREIRA, 1993). Inicialmente associava-se a glicose como único metabólito 
sinalizador do estado nutricional, cessando os mecanismos mediados nutricionalmente quando em baixos níveis de glicose e facilitando quando restabelecidos os níveis (MAYER, 1953 apud KEISLER; LUCY, 1996).

Em bovinos, hipoglicemia foi associada com a supressão de secreção de LH.

Clarke et al. (1990) apud (KEISLER; LUCY, 1996), sugeriram essa hipótese, demonstrando a inibição de secreção de pulsos de LH em ovelhas ovariectomizadas, em condições de hipoglicemia induzida pela insulina, como consequência da privação do gerador de pulso hipotalâmico de glicose.

Bucholtz e Foster

administraram injeções cerebroventriculares de 2-desoxi-glicose (uma molécula de glicose que não pode mais sofrer glicólise) em doses de modo a não afetar os níveis de glicose sérica, e verificaram que a secreção de LH pela hipófise foi suprimida. Dessa forma, é possível afirmar que a glicose de forma direta ou indireta, facilita os processos reprodutivos. No entanto, ela não pode ser considerada como um estimulante da reprodução, a partir de constatações de Rutter et al. (1989), que não verificaram aumento de secreção de $\mathrm{LH}$ em vacas no período pós-parto infundidas com glicose.

Santos e Sá Filho (2006), evidenciaram que o consumo de $\mathrm{O}_{2}$ (baseado na diferença arteriovenosa) pelo tecido ovariano é alto, considerando-se o fluxo sanguíneo insignificante quando comparados a outros órgãos e tecidos do corpo. Os autores também demonstraram que, considerando o consumo estimado de glicose e produção de lactato, o consumo equivalente de hexose pelos ovários é de cerca de 1 mols por dia, ou seja, cerca de $285 \mathrm{~g}$ de glicose/dia em vacas de leite. Dessa forma, em situações de subnutrição, onde a disponibilidade de glicose para utilização pelos tecidos reprodutivos fique limitada, é provável que haja limitação e bloqueio da atividade reprodutiva (Tabela. 1). 
Tabela. 1. Fluxo sanguíneo e consumo ou produção líquida de $\mathrm{O}_{2}$, glicose e lactato por diferentes tecidos em vacas de leite (adaptado de Santos e Sá Filho, 2006).

\section{Tecidos}

\begin{tabular}{lccc}
\hline & VDVP $^{1}$ & Fígado $^{1}$ & Ovário $^{2}$ \\
Fluxo sanguíneo, L/h & & $2.437,0$ & 1,1 \\
Consumo de O2, mMol/h & $4.217,0$ & $3.911,0$ & 960,0 \\
Produção de CO2, mMol/h & $1.927,0$ & $1.105,0$ & -- \\
Consumo de glicose, mMol/h & 4,7 & -- & 132,0 \\
Produção de glicose, mMol/h & -- & 840,0 & -- \\
Consumo de lactato, mMol/h & -- & 140,0 & -- \\
Produção de lactato, $\mathrm{mMol} / \mathrm{h}$ & 208,1 & -- & 131,0 \\
\hline
\end{tabular}

${ }^{1}$ VDVP = Vísceras drenadas pela veia porta; Dados de Reynolds et al. (2003).

${ }^{2}$ Dados de Rabiee et al. (1997).

Portanto, devido a baixa capacidade dos ruminantes em manter concentrações séricas razoavelmente constantes de glicose, sugere-se que o efeito da glicose na mediação da ativação do eixo reprodutivo é permissivo e não causal (KEISLER; LUCY, 1996).

Insulina

A insulina é um hormônio polipeptídico produzido pelas células $\beta$ nas ilhotas de Langherans no pâncreas. Sua principal função é regular os níveis de glicose no sangue, aumentando a absorção pelos tecidos (SQUIRES, 2011). Estudos têm demonstrado a insulina como mediador da informação do status nutricional do animal devido sua ligação com o metabolismo da glicose. Outros estudos demonstram a insulina como mediador dos efeitos nutricionais sobre a dinâmica folicular (WEBB et al., 2004).

A insulina combinada com a glicose parece estimular a liberação de $\mathrm{GnRH}$ hipotalâmico (ARIAS et al., 1992 apud HESS et al., 2005). Segundo Webb et al. (2004) a insulina pode facilitar a produção de IGF-1 pelo fígado, sendo importante no direcionamento dos eventos metabólicos essenciais a reprodução. Avaliações em humanos portadores de diabete mellitus, dependentes de insulina, demonstraram manifestações clínicas de hipofunção ovariana, amenorréia primária, anovulação e baixas taxas de gestação, evidenciando seu efeito na reprodução (PORETSKY; KALIN, 1987 apud PIRES et al., 2011). 
Segundo McCann e Hansel (1986) (apud FERREIRA, 1993), as concentrações de insulina variam em diferentes períodos do dia. Similarmente, variações de concentrações de insulina durante as fases do crescimento folicular também foram encontradas, sendo os níveis mais altos observados no período pré ovulatório.

A primeira ovulação pós-parto está atrasada em vacas leiteiras selecionadas para altas produções de leite em associação com menores concentrações de insulina circulante. Em um estudo, os autores investigaram o efeito de uma dieta isocalórica no intuito de aumentar as concentrações de insulina circulantes e superar o atraso da primeira ovulação pósparto. $O$ tratamento dietético induziu diferenças significativas nas concentrações de insulina plasmáticas, sendo que: a dieta que induziu alta insulina reduziu período de parto à primeira ovulação, aumentou a proporção de vacas que ovularam antes de 50 dias pós-parto, reduziu período do parto ao primeiro serviço, e melhorou taxa de concepção. Desta forma, demonstrou-se que embora a seleção genética para produção de leite pode afetar parâmetros reprodutivos em vacas leiteiras, é possível aliviar estes problemas através da manipulação nutricional (GONG et al., 2002).

O desenvolvimento folicular parece ser diretamente influenciado por alterações dos níveis de insulina, IGF-1, leptina e AGNEs (ácidos graxos não esterificados). A insulina parece agir localmente no crescimento e maturação folicular e na esteroidogênese, sendo sua restrição no pós-parto associada a redução da função ovariana. Nas células ovarianas, as GLUT-1 e GLUT-3 insulinaindependentes são os principais transportadores de glicose, enquanto GLUT-4 insulina-dependente desempenha papel de suporte. Supostamente, a insulina exerce seus efeitos de outras formas além da mediação de captação de glicose (NISHIMOTO et al., 1990 apud LEROY et al., 2009). No entanto Rabiee et al. (1997) (apud SOUZA et al., 2009) inferem que a insulina ligada ao seu receptor resulta em uma série de efeitos metabólitos, estimulando o transporte de glicose para dentro da célula, que será utilizada como principal fonte de energia pelo ovário.

IGF-1 (fator de crescimento semelhante à insulina)

A IGF-1 pertence a uma família de polipeptídeos anabolizantes com cerca de 70 aminoácidos. Estas regulam a proliferação e diferenciação de diversos tipos celulares apresentando efeito metabólico semelhante à insulina, porém, diferentemente da insulina, é produzido em diversos tecidos do corpo. Tem capacidade de atuar via endócrina ou também por mecanismos 
autócrino e parácrino (HAFEZ; HAFEZ, 2004). Foi descrita na década de 50, sendo inicialmente identificada como mediador principal do GH como promotor de crescimento com efeito nas cartilagens. No entanto, essa hipótese foi modificada ao longo dos anos, evidenciando-se sua síntese em diferentes órgãos como ovário, útero e glândula mamária, onde os efeitos não são unicamente dependentes do GH (KNOBIL; NEILL'S, 2006).

O IGF-1 parece ser importante regulador do crescimento folicular ovariano em ratas, servindo como modelos experimentais para elucidação dos efeitos do IGF-1 na foliculogênese. Receptores de IGF-1 são encontrados em grande quantidade em oócitos, células da granulosa de folículos em todas as fases, folículos pré ovulatórios e corpo lúteo (KNOBIL; NEILL'S, 2006).

Nos últimos anos o IGF-I tem sido associado como fator mediador da reprodução, sendo influenciado pelo estado nutricional. Este atua diretamente nos folículos aumentando a sensibilidade para o FSH e LH, e também no funcionamento do corpo lúteo. Suas concentrações séricas são altas 10 semanas antes do parto, diminuindo à medida que se aproxima do parto, onde são encontrados os níveis mais baixos, que vai aumentando novamente até aproximadamente 60 dias após o parto (PIRES et al., 2011).

Vacas com baixa condição corporal no pós-parto e que não melhoram sua condição corporal durante a lactação apresentam reduzidas concentrações séricas de IGF-I devido ao fato do eixo somatotrópico permanecer inativado. A hipótese é de que alterações pela nutrição na secreção de IGF-I (Figura.2) pelo fígado afetem diretamente o ovário, através de ações endócrinas do IGF-I. Concentrações mais baixas de insulina e IGF-I reduzem a resposta ovariana ao LH e FSH devido relação sinérgica entre IGF-I, insulina, LH e FSH, para crescimento folicular. Vacas em BEN produzem menos IGF-I em resposta ao $\mathrm{GH}$, pois o eixo somatotrópico não está responsivo, reduzindo a resposta do ovário às gonadotrofinas (LUCY, 2011; WEBB et al., 2004). 


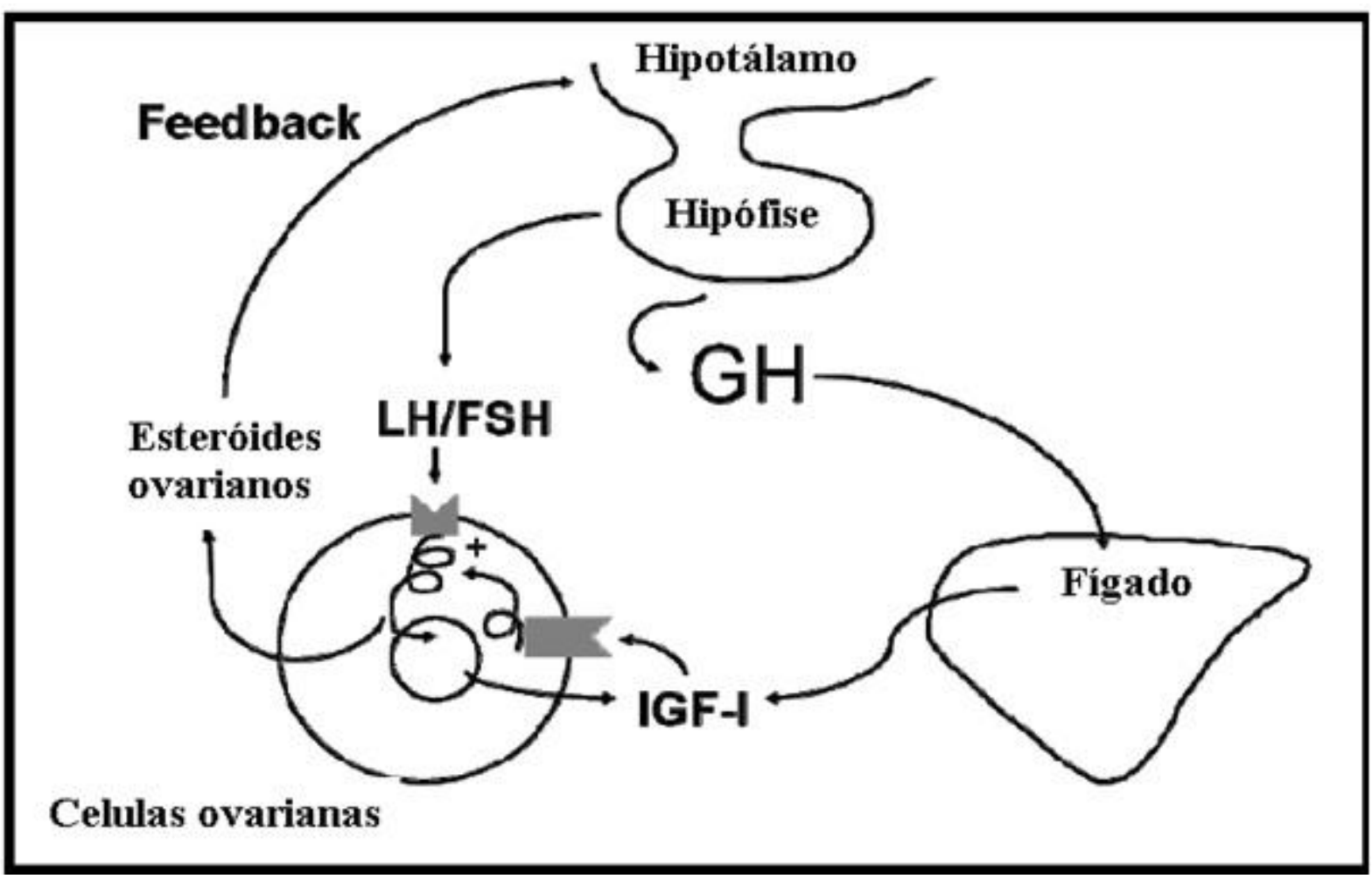

Figura.2. Esquema da atuação do GH, IGF-I, LH e FSH sinergicamente na foliculogênese e reprodução. Adaptado Lucy (2011).

\section{GH (hormônio do crescimento)}

O hormônio do crescimento, também conhecido como somatotropina, é mais conhecido por sua função de crescimento pós natal em proles. $\mathrm{O}$ GH é liberado pela adeno hipófise para a circulação sanguínea onde estimula a síntese e liberação de IGF-1 (KNOBIL; NEILL'S, 2006).

Em vacas, períodos pós-parto são acompanhados de altos níveis de $\mathrm{GH}$ no sangue, dentre os tecidos mais influenciados pelo GH estão: fígado, músculos e tecido adiposo. Em altas concentrações, o GH induz um estado insulino-resistente (evitando a fixação de glicose), para preservar a glicose para síntese de lactose mamária. Geralmente esse período dura cerca de 4 semanas pósparto (HAYIRLI, 2006).

Ações do $\mathrm{GH}$ são mediadas pelo receptor de $\mathrm{GH}$ (GHR). Maiores concentrações de GHR se encontram no fígado, músculo e tecido adiposo. No fígado produz aumento de secreção de IGF-1 que de certa forma controla secreção de GH por um mecanismo de feedback negativo (Figura. 3) (LE ROITH et al., 2001 apud LUCY, 2011). 


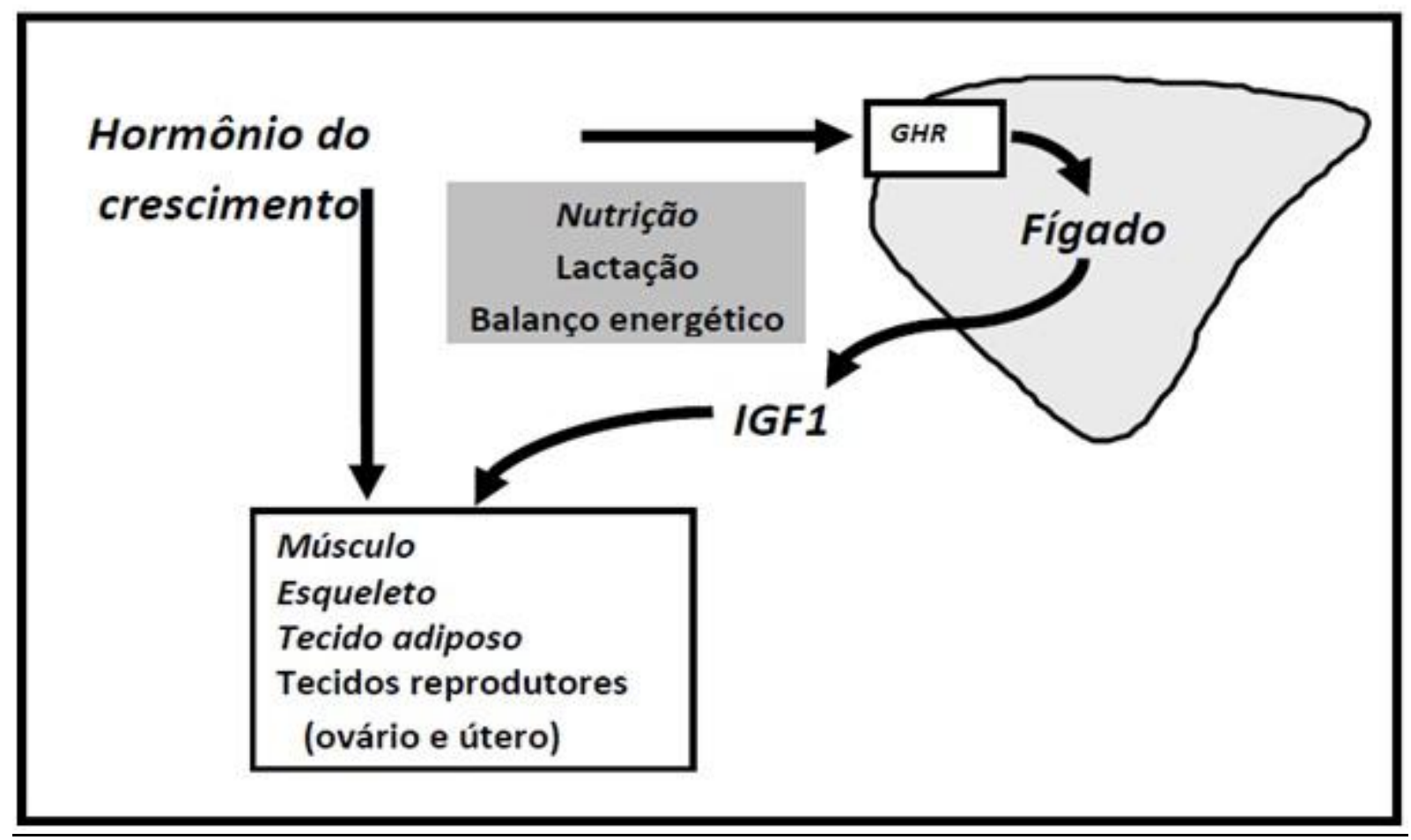

Figura.3. Interação do eixo somatotrópico em aspectos de crescimento, lactação e reprodução em bovinos.

Leptina

A leptina é um hormônio proteico de $16 \mathrm{kDa}$, conhecida como produto do gene da obesidade (ob), produzida principalmente pelos adipócitos brancos subcutâneos. Em condições de grandes reservas de energia em forma de tecido adiposo, os níveis de leptina também se encontram mais altos ativando os centros de saciedade no hipotálamo e diminuindo a ingestão de alimentos. No entanto, quando as concentrações de leptina estão baixas, na presença de baixas reservas energéticas, o consumo de alimentos é estimulado. Dessa forma, atua como um sinalizador do estatus nutricional e do balanço energético do animal (SQUIRES, 2011).
Recentemente, pesquisas têm sido realizadas no intuito de identificar o papel da leptina na reprodução. Swain et al. (2004) avaliaram o crescimento folicular, maturação oocitária e desenvolvimento embrionário pré implantação in vitro em meio de cultura contendo diferentes concentrações de leptina $(0 ; 12,5 ; 25 ; 50$ ou $100 \mathrm{ng} / \mathrm{ml})$. Os folículos, oócitos e embriões foram coletado de ratas em diferentes fases. Os autores observaram que folículos cultivados na presença de leptina recombinante resultaram em uma significativa diminuição na taxa de crescimento após 9 dias de cultura, mas não afetou o crescimento dos oócitos e desenvolvimento embrionário, foi verificado ainda efeito dose dependente, com doses 
mais elevadas de leptina inibindo o crescimento folicular. Demonstrou-se também que a leptina aumenta diretamente os níveis de insulina e de gonadotrofinas e estimulam a esteroidogênese ovariana.

A leptina é responsável pela regulação homeostática do metabolismo energético, sendo assim, o tecido adiposo branco não é apenas um tecido de reserva de energia, mas também a principal fonte produtora da leptina. $\mathrm{Na}$ produção animal a produção deste hormônio está relacionada com a deposição de gordura na carcaça, produção leiteira, conversão alimentar e mecanismos reprodutivos (SALMAN et al., 2007).

Delavaud et al. (2002) relacionaram o aumento dos níveis circulantes de leptina com um maior aporte nutricional, sendo concentrações plasmáticas relacionadas a gordura corporal e tamanho dos adipócitos. Assim, a leptina produzida e secretada é transportada, via corrente sanguínea, para tecidos alvos como as células gonadotróficas da hipófise, células da teca, granulosa e células intersticiais do ovário e endométrio, onde interage com receptores celulares específicos. Os receptores celulares da leptina (ob-R) pertencem à classe I da família de receptores citoquininas, os quais também pertencem receptores de $\mathrm{GH}$, prolactina entre outros. A presença desses receptores em todos os níveis do eixo hipotálamohipófise-gonadal, influencia e regula a reprodução (CEDDIA et al., 1998; SALMAN et al., 2007).

\section{Déficit de progesterona}

Toda vaca no pós-parto passa por um período anovular, deixando de apresentar ovulações regulares. Porém em alguns animais, esse período pode se prolongar por até 3 meses de lactação. Esse atraso na ciclicidade leva a perdas pelo baixo desempenho reprodutivo, sendo esses animais anéstricos, e quando inseminados, apresentando baixa taxa de concepção, e grandes probabilidades de perdas embrionárias (SANTOS, 2010).

Após o restabelecimento da síntese e armazenamento de LH hipofisário a atividade ovariana é restabelecida. Esse estoque é fundamental devido a diminuição dos níveis de LH durante a gestação, provocado por um feedback negativo de progesterona sobre o hipotálamo, diminuindo secreção de $\mathrm{GnRH}$ hipotalâmico, e subsequente diminuição de produção e armazenamento de $\mathrm{LH}$ hipofisário. No pós-parto, as condições de baixa progesterona permitem o acúmulo de LH na hipófise, necessitando cerca de 25 dias para restabelecimento, sendo que nesse período as concentrações de FSH não são limitantes para atividade ovariana normal (WILLIANS, 2005).

No pré-parto os níveis séricos de progesterona caem, sendo mínimas no 
momento do parto, aumentando com a primeira ovulação ou luteinização de um folículo. No entanto, esse nível de progesterona após parto, é decorrente de um corpo lúteo pequeno, pouco persistente, imaturo, com regressão precoce que dura cerca de 3 a 9 dias, e comumente não é precedido como estro (PARRA; BELTRAN, 2008).

Dados recentes sugerem que o alto consumo de alimentos no pós-parto induz ao aumento da circulação hepática e a catabolização de progesterona pelo fígado, alterando a pulsatilidade de $\mathrm{LH}$ e o desenvolvimento folicular (SANTOS; SÁ FILHO, 2006). Vacas recebendo maior quantidade de concentrado energético na forma de amido degradável no rúmen reduziram a perda de condição corporal e BEN. No entanto essa maior ingestão de energia aumentou a metabolização de hormônios esteróides como a progesterona, por um aumento de metabolismo hepático. Paralelo a isso a melhora do BEN e maiores quantidades de glicose proporcionaram maiores concentrações de insulina e IGF-1 no plasma e no líquido folicular (SANTOS, 2005 apud SANTOS e SÁ FILHO, 2006).

Características de vacas anovulares são baixas exposições a concentrações luteais de progesterona que precedem a primeira inseminação pós-parto, alterando o crescimento do folículo ovulatório, influenciando 0 endométrio a liberar prostaglandina mais cedo e demonstrando fases lúteas mais curtas. Folículos desenvolvidos em ciclos com baixa concentração de progesterona são afetados quanto a composição do fluido, aumentando a responsividade do endométrio a liberar prostaglandina, induzindo a lise do corpo lúteo e ciclos curtos (SANTOS, 2010).

Breuel et al. (1993) atribuíram a baixa taxa de fertilidade e retorno ao cio, provenientes de animais de ciclos curtos, decorrentes de oócitos de qualidade inferior, oriundos desses folículos imaturos. No estudo os autores observaram que um oócito ovulado seguido de uma fase lútea curta foi capaz de ser fertilizado e passou por um desenvolvimento precoce, sendo transportado para o útero, no entanto, mesmo com uma suplementação exógena de progesterona (acetato de melengestrol ou norgestomet) visando substituir o corpo lúteo regredindo, a gestação não se manteve. Dessa forma, a baixa fertilidade associada a uma ovulação seguida de ciclo estral com corpo lúteo de vida curta não é devido somente a regressão prematura do corpo lúteo, mas também de um oócito com um defeito inerente ou adquirido que impede seu desenvolvimento posteriormente, ou ainda de um ambiente do útero e oviduto inadequado para o desenvolvimento do embrião. 
Campanile et al. (2010) classificaram animais anovulares, incluíram fêmeas com crescimento folicular limitado, relacionando isso à uma inadequada liberação pulsátil de LH, necessário para o crescimento de folículos até o estágio pré-ovulatório. Esse quadro é mais comum em vacas de alta produção com restrições energética e proteica e baixa condição corporal. Provavelmente, baixas quantidades de estrógenos provenientes dos folículos sejam suficientes para parar o eixo reprodutivo, limitando a maturação do folículo dominante.

Autores retratam que concentrações maiores de progesterona antes e depois da inseminação melhoram a porcentagem de vacas prenhes. Estudos utilizando implantes de progestágenos antes da inseminação apresentaram maior taxa de prenhes quando comparadas a vacas com baixa progesterona (51,0\% vs $37,1 \%$ respectivamente, $P<0,001$ ), indicando o aumento de progesterona antes da inseminação como responsável pelo aumento substancial da fertilidade, sugerindo serem as baixas concentrações de progesterona durante a lactação no pós parto responsáveis pela menor taxa de prenhes após a primeira inseminação (WILTBANK et al., 2010).

Em alguns casos, a atresia folicular ocorre mesmo após um folículo alcançar a dominância. Porém, na ausência do pico de
LH, a regressão desse folículo resulta em emergência da nova onda de 2 a 3 dias após, podendo ocorrer uma sequência de até 9 ondas de crescimento foliculares antes da primeira ovulação pós-parto. Esta ocorrência parece estar relacionada à baixa frequência de pulsos de LH (1 a cada 3-4 horas) (PETER et al., 2009b). O prolongamento do período até a primeira ovulação é decorrente de uma falha na ovulação, e não a alguma alteração no crescimento folicular. Dessa forma, a falha na ovulação em ondas foliculares próximas ao pré parto são decorrentes da ineficiência do folículo em promover o pico de estrógeno necessário ao pico pré ovulatório do $\mathrm{LH}$ por feedback positivo (STAGG et al., 1995; RUIZCORTEZ; OLIVEIRA-ANGEL apud EMERICK et al., 2009).

\section{CONSIDERAÇÕES FINAIS}

Retorno a ciclicidade em bovinos ainda hoje é um fator que afeta diretamente índices de eficiência reprodutiva dos rebanhos. $\mathrm{O}$ anestro é influenciado por diversos aspectos, com destaque aos fatores endocrinológicos, ambientais, nutricionais e sociais. Dessa forma, pesquisas tem se intensificado a cerca da interação dos metabólitos nutricionais e sua influência nos mecanismos ativadores da reprodução. Portanto, é importante interpretar e elucidar esses mecanismos fisiopatológicos de forma a intervir e tentar minimizar os efeitos 
negativos do anestro pós-parto na reprodução.

\section{AGRADECIMENTOS}

Os autores agradecem a CAPESCoordenação de Aperfeiçoamento de Pessoal de Nível Superior.

\section{REFERÊNCIAS}

AHMADZADECH, A.; BARNES, M.A.; PEARSON, R.E. Effect of naloxone on serum luteinizing hormone concentration in anovulatory Holstein cows during early postpartum period. Domestic Animal Endocrinology, v.15, n.3, p.177-181, 1998. http://dx.doi.org/10.1016/S0739-

7240(98)00005-8

ATANASOV, A.S.; DINEVA, J.D.; YOTOV, S.A. Ultrasonic evaluation of uterine involution in Bulgarian Murrah buffalo after administration of oxytocin. Animal Reproduction Science, v.133, p.71-76, 2012. http://dx.doi.org/10.1016/j.anireprosci.2012. 06.002

AZEVÊDO, M.I. Temores no uso de opióides para o tratamento da dor. Dor em foco, v.1, n.4, 1998.

BELL, A.W. Regulation of organic nutrient metabolism during transition from pregnancy to early lactation. Journal of Animal Science, v.73, p.2804-2819, 1995.

BÓ, G.A.; BARUSELLI, P.S.; MARTINEZ, M.F. Pattern and manipulation of follicular development in Bos indicus cattle. Animal Reproduction Science, v.78, p.307-326, 2003. http://dx.doi.org/10.1016/S03784320(03)00097-6

BORGES, A.M.; CARVALHO, B. C.; RUAS, J.R.M. Manejo reprodutivo da vaca mestiça: estado da arte. In: CONGRESSO BRASILEIRO
DE REPRODUÇÃO ANIMAL, 2009, Belo Horizonte-MG, Anais... Belo Horizonte, 2009, CD-ROM.

BOLAND, M.P.; LONERGAN, P.; O'CALLAGHAN, D. Effect of nutrition on endocrine parameters, ovarian physiology, and oocyte and embryo development. Theriogenology, v.55, n.6, p.1323-1340, 2001. http://dx.doi.org/10.1016/S0093691X(01)00485-X

BREUEL, K.F.; LEWIS, P.E.; SCHRICK, F.N.; LISHMAN, A.W.; INSKEEP, E.K.; BUTCHER, R.L. Factors affecting fertility in the postpartum cow: role of the oocyte and follicle in conception rate. Biology of Reproduction, v.48, p.655-661, 1993. http://dx.doi.org/10.1095/biolreprod48.3.65 5

BUCHOLTZ, D.C.; FOSTER, D.L. The timing of puberty in sheep: new concepts and conceptual challenges. Journal Animal Science, v.72, n.1, p.121-129, 1994.

CAMPANILE, G.; BARUSELLI, P.S.; VECCHII, D.; PRANDI, A.; NEIGLIA, G.; CARVALHO, N.T.A.; SALES, J.N.S.; GASPARRIN, I.B.; D'IOCCHIO, N.J. Growth, metabolic status and ovarian function in buffalo (Bubalus bubalis) heifers fed low energy or high energy diet. Animal Reproduction Science, v.122, p.74-81, 2010. http://dx.doi.org/10.1016/j.anireprosci.2010. 07.005

CAMPOS, C.C.; RESENDE, E.V.; CARNEIRO, L.C.; MUNHOZ, A.K.; SANTOS, R.M. Condição ovariana de vacas holandesas no início do programa reprodutivo. Veterinária Notícias, Uberlândia, v.18. n. 2 (supl.), p. 145-147, 2012.

CEDDIA, R.P.; WILLIIAN JR, W.N.; LIMA, F.B. CARPINELLI, A.R.; CURI, R. Pivotal role of leptin in insulin effects. Brazilian Journal of Medical and Biological Research, v.31, p.715-722, 1998. 
http://dx.doi.org/10.1590/S0100-

879X1998000600001

CLARK, J.H. Lactational responses to postruminal administration of proteins and amino acids. Journal of Dairy Science, v.58, n.8, p.1178-1197,1975. http://dx.doi.org/10.3168/jds.S00220302(75)84696-0

CUBAS, A.C.; MANCIO, A.B.; LESSKIU, C.; TAHIRA, J.K. Efeito da amamentação controlada sobre a eficiência reprodutiva de vacas de corte no sul do Paraná. Revista Sociedade Brasileira Zootecnia, v.14, p.247255, 1985.

DELAVAUD, C.; FERLAY, A.; FAULCONNIER, Y.; BOCQUIER, F.; KANN, G.; CHILLIARD, Y. Plasma leptin concentration in adult cattle: effects of breed, adiposity, feeding level, and meal intake. Journal Animal Science, v.80, p.1317-1328, 2002.

DRIANCOURT, M.A. Regulation of feedback ovarian follicular dynamics in farm animals. Implications for manipulation of reproduction. Theriogenology, v.55, p.12111239, 2001.

DURAS, M.; MLYNARCZUK, J.; KOTWICA, J. Non-genomic effect of steroids on ocitocinstimulated intracellular mobilization of calcium and on prostaglandin F2 $\alpha$ and E2 secretion from bovine endometrium cells. Prostaglandins \& other Lipidis Mediat, v.76, p.105-116, 2005.

EMERICK, L.L.; DIAS, J.C.; GONÇALVES, P.E.M.; MARTINS, J.A.M.; SOUZA, F.A.; VALE FILHO, V.R.; ANDRADE, V.J. Retorno da atividade ovariana luteal cíclica de vacas de corte no pós-parto: uma revisão. Revista Brasileira de Reprodução Animal, v.33, n.4, p.203-212, 2009.

ESPASANDIN, A.C.; PACKER, I.U.; ALENCAR, M.M. Produção de leite e comportamento de amamentação em cinco sistemas de produção de gado de corte. Revista Brasileira de Zootecnia, v.30, n.3, p.702-708, 2001.

FALTYS, G.L.; CONVEY, E.M.; SHORT, R.E.; KEECH, C.A.; FOGWELL, R.L. Relationships between weaning and secretion of luteinizing hormone, cortisol and transcortin in beef cows. Journal Animal Science, v.64, n.5, p.1498-1505, 1987.

FERNANDES, C.A.C.; CARVALHO, R.J.; OLIVEIRA, E.R.; VIANA, J.M.V.; PALHÃO, M.P.; GIOSO, M.M. Efeito de diferentes doses de cloprostenol sódico no período pós-parto de vacas de corte. Ciência Animal Brasileira, Goiânia, v.13, n.3, p. 346-352, 2012.

FERREIRA, A.M. Efeito da amamentação na reprodução de vacas. Pesquisa Agropecuária Brasileira, v.27, n.1, p.27-39, 1992.

FERREIRA, A.M. Nutrição e atividade ovariana em bovinos: uma revisão. Pesquisa Agropecuária Brasileira, v.28, n.9, p.10771093, 1993.

GOKULDAS, P.P.; YADAV, M.C.; KUMAR, H.; SINGH, G.; MAHMOOD, S.; TOMAR, A.K.S. Resumption of ovarian cyclicity and fertility response in bull-exposed postpartum buffaloes. Animal Reproduction Science, v.121, p.236-241, 2010. http://dx.doi.org/10.1016/j.anireprosci.2010. 06.005

GONG, J.G.; LEE, W.J.; GARNSWORTHY, P.C.; WEBB, R. Effect of dietary-induced increases in circulating insulin concentrations the early postpartum period on reproductive function in dairy cows. Reproduction, v.123, p.419427, 2002. http://dx.doi.org/10.1530/reprod/123.3.419

GONZÁLEZ, F.H.D. Introdução a endocrinologia reprodutiva veterinária. Porto Alegre: Editora da UFRGS, 2002. 87p.

GREGG, D.W.; MOSS, G.E.; HUDGENS, R.E.; MALVEN, P.V. Endogenous opioid modulation 
of luteinizing hormone and prolactin secretion in postpartum ewes and cows. Journal Animal Science, v.63, p.838-847, 1986.

HAFEZ, B.; HAFEZ, E.S.E.; Reprodução Animal. 7. ed. Barueri: Manole, 2004. 513p.

HAYIRLI, A. The role of exogenous insulin in the complex of hepatic lipidosis and ketosis associated with insulin resistance phenomenon in postpartum dairy cattle. Veterinary Research Communications, v.30, n.7, p.749-774, 2006. http://dx.doi.org/10.1007/s11259-006-33206

HESS, B.W.; LAKE, S.L.; SCHOLLEGERDES, E.J.; WESTON, T.R.; NAYIGIHUGU, V.; MOLLE, J.D.C.; MOSS, G.E. Nutricional controls of beef cow reproduction. Journal Animal Science, v.83, p.90-106, 2005.

HUSSEIN, H.A.; ABDEL-RAHEEM, S.M. Effect of feed intake restriction on reproductive performance and pregnancy rate in Egyptian buffalo heifers. Tropical Animal Health and Production, v.45, p.1001-1006, 2013. http://dx.doi.org/10.1007/s11250-012-03249

KADOKAWA, H.; YAMADA,Y. Enhancing effect of acute fasting on ethanol suppression of pulsatile luteinizing hormone release via an estrogen-dependent mechanism in Holstein heifers. Theriogenology, v.51, n.4. p.673-680, 1999. http://dx.doi.org/10.1016/S0093691X(99)00016-3

KEISLER, D.H.; LUCY, M.C. Perception and interpretation of the effects of undernutrition on reproduction. Journal Animal Science, v.74, p.1-17, 1996.

KNOBIL, E.; NEILL'S, J.D. Physiology of Reproduction. 3. ed. New York: Elsevier, 2006. p.3254.

LAMB, G.C.; MILLER, B.L.; LYNCH, J.M.; GRIEGER, D.M.; STEVENSON, J.S. Sukling twice daily, but not milking twice daily in the presence of cow's own calf, prolongs postpartum anovulation. Journal Animal Science, v.77, p.2207-2218, 1999.

LAMB, G. C. Efeito da nutrição e da amamentação no anestro. In: CURSO NOVOS ENFOQUES NA PRODUÇÃO E REPRODUÇÃO DE BOVINOS, 13., 2009, Uberlândia-MG, Anais... Uberlândia 2009, CD-ROM.

LAMB, G. C.; LYNCH, J. M.; GRIEGER, D.M.; MINTON, J. E. e STEVENSON, J. S. Ad libitum suckling by an unrelated calf in the presence or absence of a cow's own calf prolongs postpartum anovulation. Journal Animal Science, v.75, p.2762-2769, 1997.

LEROY, J.L.M.R.; VANHOLDER, T.; VAN KNEGSEL, A.T.M.; GARCIA-ISPIERTO, I.; BOLS, P.E.J. Priorização de nutrientes em vacas leiteiras no pós-parto imediato: discrepância entre metabolismo e fertilidade? In: CURSO NOVOS ENFOQUES NA PRODUÇÃO E REPRODUÇÃO DE BOVINOS, 13., 2009, Uberlândia-MG, Anais... Uberlândia 2009, CD-ROM

LUCY, M.C. Glicose sanguínea em ruminantes: Um metabólito crítico para a reprodução de vacas em lactação. In: CURSO NOVOS ENFOQUES NA PRODUÇÃO E REPRODUÇÃO DE BOVINOS, 15., 2011, Uberlândia-MG, Anais... Uberlândia 2011, CD-ROM.

MANCIO, A.B.; HERNÁNDEZ, F.I.L.; FONSECA, F.A. Amamentação controlada no desempenho reprodutivo de vacas de corte. Arquivo Brasileiro de Medicina Veterinária e Zootecnia, v.51, n.1, p.75-80, 1999.

MORALES, J.T.; CAVESTANY, D. Anestro posparto en vacas lecheras. Veterinaria, n.185, p.19-27, 2012.

MWANSA, P. B.; CREWS JR., D. H.; WILTON, J. W.; KEMP, R. A. Multiple trait selection for maternal productivity in beef cattle. Journal 
of Animal Breeding and Genetics, v. 119, n. 6, p. 391-399, 2002. http://dx.doi.org/10.1046/j.14390388.2002.00363.x

PARRA, B.C.; BELTRAN, M.P. Interação entre nutrição e reprodução em vacas de corte. Revista Científica Eletrônica de Medicina Veterinária, ano VI, n.11, 2008.

PECK, D. D.; THOMPSON, F. N.; JERNIGAN, A. KISER, T. E. Effect of morphine on serum gonadotropin concentrations in postpartum beef cows. Journal Animal Science, v.66, p.2930-2936, 1988.

PEROTTO, D.; ABRAHÃO, J.J.S.; KROETZ, I.A. Intervalo de partos de fêmeas bovinas Nelore, Guzerá x Nelore, Red Angus x Nelore, Marchigiana $x$ Nelore e Simental $x$ nelore. Revista Brassileira de Zootecnia, v.35, n.3, p.733-741, 2006.

PETER, A.T.; LEVINE, H.; DROST, M.; BERGFELT, D.R. Compilation of classical and contemporary terminology used to describle morphological aspectas of ovarian dynamics in cattle. Theriogenology, v.71, p.1343-1357, 2009a.

http://dx.doi.org/10.1016/j.theriogenology.2 008.12 .026

PETER, A.T.; VOS, P.L.A.M.; AMBROSE, D.J.; Postpartum anestrus in dairy cattle. Theriogenology, v.71, p.1333-1342, 2009b. http://dx.doi.org/10.1016/j.theriogenology.2 008.11 .012

PINHEIRO, V.G.; CURY, J.R.L.M.; SATRAPA, R.A.; TRINCA, L.A.; LOUREIRO, B.; BARROS, C.M. Evaluation of the hypothalamuspituitary axis response to exogenous $\mathrm{GnRH}$, estradiol benzoate, and $\mathrm{LH}$ during the postpartum period in Nellore cows. Theriogenology, v.79, p.797-802, 2013. http://dx.doi.org/10.1016/j.theriogenology.2 012.12 .006
PIRES, A.V.; BIEHL, M.V.; SUSIN, I.; CRUPPE, L.H.; NEPOMUCENO, D.D.; ROCHA, F.M.; FERREIRA, E.M. Interrelações entre nutrição e reprodução: fatores que potencializam 0 desempenho reprodutivo. In: SIMBOV MTSIMPÓSIO MATO-GROSSENSE DE BOVINOCULTURA DE CORTE, 1., 2011, Cuiabá, Anais... Cuiabá, 2011, p.263-292.

PONSART, C.; KHIREDDINE, B.; PONTER, A.A.; HUMBLOT, P.; MIALOTL, J.P.; GRIMARDLA, B. Influence of the type of energy supply on $\mathrm{LH}$ secretion, follicular growth and response to estrus synchronization treatment in feedrestricted sucker beef cows. Theriogenology, v.54, p.1373-1387, 2000. http://dx.doi.org/10.1016/S0093691X(00)00460-X

RABASSA, V. R.; PFEIFER, L. F. M.; SCHNEIDER, A.; LUZ, E. M.; COSTA, E. R. M.; CORRÊA, M. N. Anestro pós-parto em bovinos: mecanismos fisiológicos e alternativas hormonais visando reduzir este período uma revisão. Revista da FZVA, Uruguaiana, v.14, n.1, p.139-161, 2007.

RHODES, F.M.; MCDOUGALL, S.; BURKE, C.R.; VERKERK, G.A.; MACMILLAN, K.L. Invited review: Treatment of cows with an extended postpartum anestrous interval. Journal Dairy Science, v.86, p.1876-1894, 2003. http://dx.doi.org/10.3168/jds.S00220302(03)73775-8

RIVIER, C.; RIVEST, S. Effects of stress on on the activity of the hypotlalamic-pituitarygonadal axis: peripheral and central mechanisms. Biology of Reproduction, v.45, p.523-532, 1991. http://dx.doi.org/10.1095/ biolreprod45.4.523

RUTTER, L.M.; SNOPEK, R.; MANNS, J.G. Serum concentrations of IGF-I in postpartum beef cows. Journal Animal Science, v.67, p.2060-2066, 1989.

SALMAN, A.K.D.; RAPHAE, B.C.; GIACHETTO, P.F. Gene da leptina em ruminantes. Revista Electrônica de Veterinária, v.3, n.12, 2007. 
SANTOS, F.D.; BRAZ, M.A.; MANGOLD, M.A. Influência do bezerro na duração do anestro em vacas de corte. Ciências Agrárias Saúde, Andradina, v.3, n.2, p.48-53, 2003.

SANTOS, J.E. Vacas anovulares (anestro/cisto/dinâmica folicular) fisiologia, fatores de rirsco, impacto e tratamento In: CURSO NOVOS ENFOQUES NA PRODUÇÃO E REPRODUÇÃO DE BOVINOS, 14., 2010, Uberlândia-MG, Anais... Uberlândia, 2010, CD-ROM.

SANTOS, J. E. P.; SÁ FILHO, M. F. Biotecnologia da reprodução em bovinos. In: SIMPÓSIO INTERNACIONAL DE REPRODUÇÃO ANIMAL APLICADA, 2., 2006, São Paulo. Anais... São Paulo, 2006, CD-ROM.

SENGER, P.L. Pathways to pregnancy and parturition. 2. ed. Pullman, USA: Current Conceptions, 2003. p.373.

SOUZA, F.A.; CANISSO, I.F.; BORGES, A.M.; VALE FILHO, V.R.; LIMA, A.L.; SILVA, E.C. Restrição alimentar $e$ os mecanismos endócrinos associados ao desenvolvimento folicular ovariano em vacas. Revista Brasileira de Reprodução Animal. Belo Horizonte, v.33, n.2, p.61-65, 2009.

SQUIRES, E.J. Aplied Animal Endocrinology, Cabi Publishing. 1. ed. 2011. p.312.

STEVENSON, J.S.; KNOPPEL, E.L.; MINTON, J.E.; SALFEN, B.E.; GARVERICK, H.A. Estrus, ovulation, luteinizing hormone, and sucklinginduced hormones in mastectomized cows with and without unrestricted presence of the calf. Journal Animal Science, v.72, p.690699, 1994.

SWAIN, J.E.; DUNN, R.D.; MCCONNELL, D. GONZALES-MARTINEZ, J.; SMITH, G.D. Direct effects of leptin on mouse reproductive function: regulation of follicular oocyte, and embryo development. Biology of Reproduction, v.71, p.1446-1452, 2004. http://dx.doi.org/10.1095/biolreprod.104.03 3035

TAMMINGA, S.; LUTEIJN, P.A.; MEIJER,R.G.M. Changes in composition and energy contento $f$ liveweight loss in dairy cows with time after parturition. Livestock Production Science, v.52, p.31-38, 1997.

THOMAS, M.G.; BAO, B.; WILLIAMS, G.L. Dietary fats varying in their fatty acid composition differentially influence follicular growth in cows fed isoenergetic diets. Journal Animal Science, v.75, p.2512-2519, 1997.

TRIBIOLI, R. A. Efeitos da estimulação elétrica na formação e liberação de opióides endógenos. Revista Unorp, São José do Rio Preto, v.5, n.12, p.49-61, 2004.

WEBB, R.; GARNSWOTHY, P.C.; GONG, J.C.; ARMSTRONG, D.G. Control of follicular growth: Local interactions and nutritional influences. Journal Animal Science, v.82, p.63-74, 2004.

WHISNANT, C.S.; THOMPSON, F.N.; KISER, T.E.; BARB, C.R. Opioid inhibition of luteinizing hormone secretion during the postpartum period in suckled beef cows. Journal Animal Science, v.63, p. 1445-1448, 1986.

WILLIANS, G.L. Fisiologia e manejo reprodutivo de vacas de corte pós-parto. In: CURSO NOVOS ENFOQUES NA PRODUÇÃO E REPRODUÇÃO DE BOVINOS, 11., 2005, Uberlândia-MG, Anais... Uberlândia, 2005, CD-ROM.

WILLIAMS, G.L. Implicações da amamentação e manejo da cria na eficiência reprodutiva futura de vacas de corte. In: CURSO NOVOS ENFOQUES NA PRODUÇÃO E REPRODUÇÃO DE BOVINOS. 2001, Uberlândia-MG, Anais... Uberlândia, 2001, CD-ROM. 
WILLIAMS, G. L.; McVEY, W. R.; HUNTER, J. F. Mammary somatosensory pathways are not required for sucklingmediated inhibition of luteinizing hormone secretion and delay of ovulation in cows. Biology of Reproduction, v.49, p.1328-1337, 1993. http://dx.doi.org/10.1095/

biolreprod49.6.1328

WILTBANK, M.C.; NASCIMENTO, A.B.; PICCINATO, C.A.; SOUZA, A.H.; SARTORI, R.; CUNHA, A.P. Importância da progesterona antes da inseminação artificial na eficiência reprodutiva de vacas leiteiras em lactação. In: CURSO NOVOS ENFOQUES NA PRODUÇÃO E REPRODUÇÃO DE BOVINOS, 14., 2010, Uberlândia-MG, Anais... Uberlândia 2010, CD-ROM.

WILTBANK, M.C.; GÜMEN, A.; SARTORI, R. Physiological classification of anovulatory conditions in cattle. Theriogenology, v.57, p.21-52, 2002. http://dx.doi.org/10.1016/S0093691X(01)00656-2

YAVAS, Y.; WALTON, J.S. Postpartum acyclicity in sucled bbef cows: a rewie. Theriogenology, v. 54, p. 25-55, 2000. http://dx.doi.org/10.1016/S0093-

691X(00)00323-X

Recebido para publicação em 20/07/2012

Revisado em 26/11/2013

Aceito em 28/02/2014 